\title{
Seasonal variations of the ichthyoplankton assemblage in the Yangtze Estuary and its relationship with environmental factors
}

\author{
Hui Zhang ${ }^{\text {Corresp., }}{ }^{1,2,3}$, Weiwei Xian ${ }^{1,2,3}$, Shude Liu ${ }^{1}$ \\ ${ }^{1}$ CAS Key Laboratory of Marine Ecology and Environmental Sciences, Institute of Oceanology, Chinese Academy of Sciences, Qingdao, China \\ 2 Laboratory for Marine Ecology and Environmental Science, Qingdao National Laboratory for Marine Science and Technology, Qingdao, China \\ ${ }^{3}$ Center for Ocean Mega-Science, Chinese Academy of Sciences, Qingdao, China \\ Corresponding Author: Hui Zhang \\ Email address: zhanghuifirst@gmail.com
}

Seasonal variations of the ichthyoplankton assemblage and its relationship with the environment were analyzed based on four seasonal surveys during 2012. Historical data was collected to be compared with results from previous years in order to indicate the seasonal and inter-annual variation of the ichthyoplankton assemblage in the Yangtze Estuary and the adjacent waters. A total of 3,688 individuals belonging to 5 orders, 9 families, and 15 species were collected. No samples were collected in the winter cruise. In 2012, all samples were separated into four ecotypes, which is comparable with the historical data from previous years. The Engraulis japonicus was the most abundant species of all teleost fishes. The $E$. japonicus was captured in every season and contributed the most to the abundance of ichthyoplankton, which was greater than that of previous years. This result may be due to the periodic fluctuations of $E$. japonicus or from the displacement of spawning grounds offshore for environmental reasons. The diversity indices of the assemblage were significantly different among seasons, with the number and abundance of the species peaking in the spring, while richness, evenness and diversity indices peaked in the autumn. The species richness of the ichthyoplankton varied from 0.74-1.62, the Pielou evenness index varied from 0.10-0.49 and the Shannon-Wiener index varied from 0.19-1.04. The results of CCA analysis showed that the major factors affecting the ichthyoplankton assemblage differed throughout the seasons. Chla was the key factor affecting the ichthyoplankton in 2012 . These seasonal and inter-annual variations likely resulted from migrations associated with fish spawning as well as the environment. Compared with data from previous studies, the relationship between the assemblage structure of ichthyoplankton and corresponding environmental variables have undergone a decline. 
1 Title

2 Seasonal variations of the ichthyoplankton assemblage in the Yangtze Estuary and its

3 relationship with environmental factors

4

\section{Authors}

6 Hui Zhang ${ }^{1,2,3^{*}}$, Weiwei Xian ${ }^{1,2,3^{*}}$, Shude Liu ${ }^{1}$

7 1. CAS Key Laboratory of Marine Ecology and Environmental Sciences, Institute of Oceanology,

8 Chinese Academy of Sciences, Qingdao, 266071, China

9 2. Laboratory for Marine Ecology and Environmental Science, Qingdao National Laboratory for 10 Marine Science and Technology, Qingdao 266237, China

11 3. Center for Ocean Mega-Science, Chinese Academy of Sciences, 7 Nanhai Road, Qingdao, 12 266071, China

*Corresponding author:

Hui Zhang,

17 e-mail: zhanghui@qdio.ac.cn

18 Weiwei Xian,

19 e-mail:wwxian@qdio.ac.cn 
21

22

\section{Abstract}

Seasonal variations of the ichthyoplankton assemblage and its relationship with the environment were analyzed based on four seasonal surveys during 2012. Historical data was collected to be compared with results from previous years in order to indicate the seasonal and inter-annual variation of the ichthyoplankton assemblage in the Yangtze Estuary and the adjacent waters. A total of 3,688 individuals belonging to 5 orders, 9 families, and 15 species were collected. No samples were collected in the winter cruise. In 2012, all samples were separated into four ecotypes, which is comparable with the historical data from previous years. The Engraulis japonicus was the most abundant species of all teleost fishes. The E. japonicus was captured in every season and contributed the most to the abundance of ichthyoplankton, which was greater than that of previous years. This result may be due to the periodic fluctuations of E. japonicus or from the displacement of spawning grounds offshore for environmental reasons. The diversity indices of the assemblage were significantly different among seasons, with the number and abundance of the species peaking in the spring, while richness, evenness and diversity indices peaked in the autumn. The species richness of the ichthyoplankton varied from $0.74-1.62$, the Pielou evenness index varied from 0.10-0.49 and the Shannon-Wiener index varied from 0.191.04. The results of CCA analysis showed that the major factors affecting the ichthyoplankton assemblage differed throughout the seasons. Chla was the key factor affecting the ichthyoplankton in 2012. These seasonal and inter-annual variations likely resulted from migrations associated with fish spawning as well as the environment. Compared with data from previous studies, the relationship between the assemblage structure of ichthyoplankton and corresponding environmental variables have undergone a decline. 


\section{Introduction}

The Yangtze Estuary is a transitional region between freshwater and the sea, which is in an advantageous geographical location with a distinct ecological environment. Profiting from the freshwater runoff of the Yangtze River, the Taiwan Warm Current, the East China Sea Coastal Current, and the Yellow Sea Coast Current, the Yangtze River has become an excellent spawning and nursing ground for an array of economic fish species and a crucial fishery ground in China (Luo and Shen, 1994). However, the Yangtze River basin, especially the estuary area, is characterized by a high level of industrialization and urbanization (Chai et al, 2009), exposing the estuary to anthropogenic agents from the populated areas and industries upstream of the estuary. The construction and operation of the Three Gorges Reservoir has resulted in short-term and long-term impacts not only on the ecosystem of the Yangtze Estuary, but also in the distribution and community structure of marine organisms (Xian et al, 1994). Due to the intensity of trawling operations and environmental pollution, the structure of marine fishery resources was characterized by a recession in economic fish species as well as the variety of species (Shan and Jin, 2011). Therefore, it is necessary to determine the relationship between the ichthyoplankton assemblage and the environmental variation.

The spatial and temporal variation of ichthyoplankton assemblages has been widely studied in the field of marine ecology(such as Yang et al, 1990; Zhu et al, 2002; Zhong et al, 2007; Zhang et al, 2015;2016.). With better insight into the state of the Yangtze Estuary, many domestic scholars have studied the seasonal variation in the composition and biodiversity of species, as well as the characteristics of the ichthyoplankton assemblage structure and its relationship with environmental factors such as the depth, dissolved oxygen, temperature, and salinity in this region. In the springs of 1999 and 2001, Liu et al (2008) reported the taxonomic identification of a total of 11540 ichthyoplankton individuals in the Yangtze Estuary, which belonged to 11 orders, 18 families, and 32 species. Salinity, depth, dissolved oxygen, and total suspended particulate matter were the major factors affecting the ichthyoplankton assemblages in the study areas. Wei et al (2012) reported that a total of 93 ichthyoplankton samples were collected at 15 
stations in Hangzhou Bay in the summers from 2004 to 2010. As a result, 233 eggs and 29825 larvae were obtained. The correlation was significant between ichthyoplankton logarithm density and factors of hydrological conditions. The goal of this paper is to show the characteristics of the ichthyoplankton assemblage by gathering data on species composition and biodiversity in the Yangtze Estuary from four cruises that took place in 2012, as well as to reveal the relationship between the spatial-temporal distribution patterns in the ichthyoplankton assemblage and environmental factors. The results could provide a scientific basis for the management and sustainable utilization of fishery resources in the Yangtze Estuary.

\section{Materials and Methods}

\section{Data collection}

A total of 40 sampling stations were located at the Yangtze Estuary and its adjacent waters $\left(30^{\circ} 45^{\prime}-32^{\circ} 00^{\prime} \mathrm{N}, 121^{\circ} 00^{\prime}-123^{\circ} 20^{\prime} \mathrm{E}\right)$ (Fig.1). Samples were collected using the trawl, guided by the "Specification of Oceanographic Investigation" (GB12763-2007) in February, May, August, and November of 2012. This gear has a horizontal opening of $0.8 \mathrm{~m}$ and a vertical opening of 2.8 $\mathrm{m}$ (mesh size of $0.5 \mathrm{~mm}$ ). The trawl was monitored horizontally with the vessel speed of approximately 2 knots, lasting 10-min at each station. Samples taken from each trawl were immediately preserved in a 5\% formalin buffer for later sorting. Real-time data collected on the environmental parameters of the water column included temperature $(\mathrm{T})$, salinity $(\mathrm{S})$, total nitrogen (TN), total phosphorus (TP), $\mathrm{pH}$, suspended matter (SPM), depth (D), dissolved oxygen (DO), chemical oxygen demand (COD), and chlorophyll a (Chla). The collection of data was under the guidance of the "Specification of Oceanographic Investigation" (GB12763-2007). Field experiments were approved by Three Gorges Project Construction Commission of the State Council, China (Project Numer:JJ2013011)

\section{Species identification}

At the laboratory, fish eggs and larvae were counted and sorted to the lowest possible 
99

100

101

102

103

104

105

106

107

108

109

6

taxonomic level at each station according to the morphological characteristics found in the literature (Zhang et al, 1985; Cheng and Zheng, 1987; Wu et al, 2012;). These were classified into different ecotypes by their distinct ecological habits based on the descriptions in the literature (Yang et al, 1990; Luo and Shen, 1994). Numerous fish eggs and larvae that lacked clear morphological features could not be identified using this approach, so molecular identification was applied to prevent misidentification.

\section{Data analyses}

The abundance of ichthyoplankton was standardized and expressed as the total number of individual fish eggs and larvae per 10 min-trawling (ind/trawl). The dominant species were determined using the Index of Relative Importance (IRI) developed by Zhu et al (2002):

$$
I R I=\mathrm{N} * 100 \% * \mathrm{~F} * 100 \%
$$

$\mathrm{N} * 100 \%$ and $\mathrm{F} * 100 \%$ are the relative abundance and frequency of occurrence, respectively. The IRI of the dominant species should be greater than 100 .

The Margalef's richness (D), Shannon-Wiener index $\left(\mathrm{H}^{\prime}, \log _{\mathrm{e}}\right)$, and Pielou's evenness $\left(\mathrm{J}^{\prime}\right)$ were calculated for each station. Related equations were as follows ( Ludwig and Reynolds, 1988; Qian and Ma, 1994):

$$
\begin{gathered}
D=(S-1) / \ln N \\
H^{\prime}=-\sum_{i=1}^{S} P_{i} \operatorname{gn} P_{i} \\
J^{\prime}=H^{\prime} / \ln S
\end{gathered}
$$

Where "S" is the number of species, "N" is total individuals, and "Pi" is the proportion of fish species individuals to the total individuals.

The homoscedasticity was measured with the method Levene's test, after which a one-way ANOVA was performed to assess the difference in abundance, biomass, species richness, and biodiversity index among four cruises. When a significant difference was detected, the Duncan's 
125

126

127

128

129

130

131

132

133

134

135

136

137

138

139

test was applied for multiple comparisons. Canonical correspondence analysis (CCA) was applied to analyze the correlation between environmental factors and the distribution pattern of ichthyoplankton assemblages. To eliminate the effects of a few dominant species, numerous zeros in the species data, and a highly variable value in environmental data, all data matrix were transformed by $\log (\mathrm{x}+1)$.

All maps were drawn with Surfer 8.0 and statistical analyses were performed with PRIMER 5.0, SPSS 16.0 and CANOCO 4.5.

\section{Results}

\section{Species composition}

A total of 3688 individuals, including 689 fish eggs and 2999 larvae from 4 cruises, were sorted. All samples belonged to 7 orders, 12 families, and 15 species including one unidentified species (Table 1). The abundance and biomass of Engraulidae, were dominant in 2012.

According to the habitats and distribution characteristics of ichthyoplankton, 4 ecotypes were included in this study (Table. 1):

Fresh water species included $P$. engraulis, which complete their entire life cycle in fresh water. This species is distributed in fresh waters or oligo-salt waters adjacent to the inner sides of the estuary and had the fewest individuals, accounting for $1.97 \%$ of the entire abundance in four seasons.

Brackish water species, which use the estuary as a habitat but which complete the early developmental stages in the waters close to the estuary, include catadromous species and anadromous species. These species include C. nasus, C. mystus, C. spinosus, H. sajori, and one species belonging to Takifugu, accounting for $11.30 \%$ of the total abundance.

Coastal species typically gather in shallow coastal waters for reproduction and development in the spring and summer months and migrate to abyssal regions in winter. Four species were included: A. commersoni, L. polyactis, A. bleekeri, and M. monodactylus, accounting for $4.55 \%$ of the total abundance. 
152

153

154

155

156

157

158

159

160

161

162

163

164

165

166

167

168

169

170

171

172

173

174

175

176

177

178

The marine species that migrate to the profundal zone $(>30 \mathrm{~m})$ for feeding as they hit adulthood then returns to estuary or coastal waters for spawning and breeding includes $E$. japonicus, S. japonicus, T. japonicus, S. acua, and L. litulon, which were the greatest contributors to the total abundance, accounting for $82.30 \%$.

The greatest number of species were collected in the spring, including 3 brackish water species, 4 coastal species, and 3 marine species.This was followed by autumn with 9 species collected, including 4 brackish water species, 2 coastal species, and 3 marine species, The least number of species were caught in the summer, including 1 fresh water species, 1 marine species, 3 brackish water species, and 3 coastal species. In the summer, ichthyoplankton assemblages were dominated by brackish water and coastal species, while coastal species and brackish water species were dominant in the spring and autumn months, respectively.

E.japonicus, C. mystus, A. commersoni, A. bleekeri, and C. spinosus were widespread species, which were captured in all four seasons.Conversely, 7 species $(54.55 \%$ of the total species) were captured only in single season; S. japonicus, L. polyactis and M. monodactylus were only collected in the spring, P. engraulis was only collected in the summer, and S. acua, H. sajori, T. japonicus were only captured in the autumn. The distribution pattern of ichthyoplankton assemblages varied with seasonal changes due to the ecological habits of the species as well as their tendencies toward differing seasonal compositions. .

The Index of Relative Importance (IRI) was used to discuss the dominant species. Species with an index greater than 1000 and a range from 100 to 1000 were considered a dominant species and common species, respectively. These factors combined indicated the important species. A clear variation occurred in the composition of the dominant species in every season (Table 2). E.japonicus and $C$. nasus were the dominant species which contributed the most $(98.63 \%)$ to the total abundance, followed by E. japonicus which occupied $93.80 \%$ in the spring, as indicated in Table 2. E. japonicus occupied the greatest proportion of the abundance in the spring and autumn. The characteristics and composition of the dominant species and the variation in the degree of dominance showed a distinct difference during three investigations, 
179 180

\section{1}

182

183

184

which indicated the seasonal variations in the ichthyoplankton assemblage structure.

\section{Spatial and temporal variation}

The spatial distribution of the ichthyoplankton abundance in the Yangtze Estuary in 2012 showed significant seasonal variation (Fig 2), with the highest abundance in the spring and the lowest in the autumn.

A total of 2604 individuals were captured in the spring, including 317 fish eggs and 2287 larvae. Larvae were widespread, with the exception of the river channel and the northern locations of the investigation areas. The most widely distributed species was E. japonicus, followed by A. bleekeri, C. mystus, C. spinosus, and L. polyactis. In total, 366 individuals were recorded in the summer, including 120 fish eggs and 246 larvae, which were primarily distributed in the river channel and the southern and eastern portions of the study areas. $E$. japonicus had the greatest number of larvae, followed by P. engraulis and C. mystus, which shared a similar distribution range. Only 76 larvae were collected in the autumn, and no fish eggs; these were mainly distributed in the river channel and the southern portion of the study areas, with the C.nasus as the majority, followed by E. japonicus, A. bleekeri, A.commersoni, and $H$. sajori.

\section{Biodiversity}

The statistical result of Levene's test $(\mathrm{dfl}=2, \mathrm{df} 2=9$, sig $=0.165>0.05)$ indicated that the difference of homoscedasticity of the index is not significant. We then used the One-way ANOVA test for further analysis. The One-way ANOVA test revealed that a significant difference occurred among three diversity indexes during four seasons ( $\mathrm{df}$ of inter-season=2, $\mathrm{df}$ of intra-season=9, $\mathrm{F}=4.601, \mathrm{P}=0.0095<0.01)$.

According to the results, autumn presented the highest diversity indexes while spring presented with the lowest (Table 3). Furthermore, according to the result of multiple comparisons, all the diversity indexes had a significant difference between spring and autumn 
$206(\mathrm{P}<0.01)$. Furthermore, $H^{\prime}$ and $J^{\prime}$ between spring and summer as well as $J^{\prime}$ between summer 207 and winter also occurred with a significant difference. However, no significant difference was 208 detected for $D$ between spring and summer $(\mathrm{F}=3.24, \mathrm{P}=0.10>0.05)$ as well as for $D(\mathrm{~F}=4.30$, $209 \mathrm{P}=0.08>0.05)$ and $H^{\prime}(\mathrm{F}=2.96, \mathrm{P}=0.07>0.05)$ between summer and autumn.

210

211

212

213

214

215

216

217

218

219

220

221

222

223

224

225

226

227

228

\section{CCA analysis}

The relationships between the environmental factors and the species were clarified in the CCA ordination diagram using the data from 15 species and the set of 10 environmental factors. The first axis (eigenvalues $=0.497$ ) and the second axis (eigenvalues $=0.290$ ) of the CCA plot explained $14.4 \%$ of "species data" variation and $65.6 \%$ of variation in "species-environment relation". The species-environment correlation coefficients of these two axes were 0.832 and 0.621, respectively. The Monte-Carlo test (Table 4) indicated that Chla was the key environmental factor affecting ichthyoplankton assemblages $(\mathrm{P}<0.05)$. As shown in the diagram, the first axis was strongly correlated with Chla, SPM, TP, COD, DO, and the remaining environmental factors displayed a higher correlation with axis 2 than axis 1. SPM, Chla, TP, and temperature exerted a positive effect on the first axis.In addition, depth showed a positive correlation and TN showed a negative correlation with the second axis, respectively. The CCA ordination plot of sampling stations (Fig 3) revealed that in the spring, stations were located in an area with a significantly higher level of dissolved oxygen, $\mathrm{TN}, \mathrm{pH}$, and salinity. The location of sampling stations in the summer were relatively scattered and mainly characterized by higher levels of TN, TP, Chla, SPM, temperature, and dissolved oxygen values. As for the investigation areas in the autumn, sampling stations were mainly distributed in areas with higher $\mathrm{pH}$ and salinity values.

As shown in the CCA ordination plot of ichthyoplankton species (Fig 4), the correlation between environmental factors and the distribution of different species was inconsistent. $E$. japonicus showed a strong relationship with dissolved oxygen and was less affected by the remaining factors, while $S$. japonicus was mainly affected by TP, which indicated that the 
233

234

235

236

237

238

239

240

241

242

243

244

245

246

247

248

249

250

251

252

253

254

255

256

257

258

259

distribution pattern of different species belonging to the same ecotype may be affected by different environmental factors. L. polyactis and A.commersoni also revealed a significant positive correlation with dissolved oxygen and were mainly distributed in the region of higher dissolved oxygen content. C. spinosus showed a distinct distribution pattern positively associated with the higher value of Chla, SPM, and temperature. The distribution pattern of C. nasus was positively correlated with deeper and higher concentration of nutrients areas.

Species such as H. sajori (hesa), A. bleekeri (Albl), M. monodactylus (Mimo), and S. acua (syca) had a positive correlation with $\mathrm{pH}$ and salinity but A. bleekeri had lower demand for $\mathrm{pH}$ and salinity than the other three species.

\section{Discussion}

The ichthyoplankton assemblages in estuaries are complex both in species composition and distribution. Studies show that the organization of ichthyoplankton in estuarine systems is influenced by the interactive effects of a multitude of biotic and abiotic processes. Biological factors include the location, timing and manner of spawning, larval life history, larval behavior, rates of predation, and feeding (Leis 1991; Azeiteiro 2006). Physical factors include salinity (Whitfield 1999), temperature (Blaxter 1992), turbidity (Islam et al. 2006), dissolved oxygen (Rakocinski et al. 1996), depth (Wantiez et al. 1996), river flow (Faria et al. 2006), sediment characteristics, and hydrographic events such as currents, winds, eddies, upwelling, and stratification of the water column (Gray 1993). The present study was based on surveys during four seasons in 2012. Our aim was to provide detailed characterizations of the ichthyoplankton assemblage in 2012 and to evaluate the influence of environmental factors on the spatial distribution and intra-annual variations of ichthyoplankton assemblages associated with the Yangtze Estuary.

\section{Species composition and seasonal variation}

In the last decades, many scholars have reported the community structure and biodiversity of ichthyoplankton assemblages and their relationship with environmental factors. The study of 
260 Yang et al (1990), was carried out from 1985 to 1986 with 10 cruises in Yangtze Estuary, 261 collecting 94 species. Another study based on four cruises in 2007 collected 45 species (Liu and 262 Xian, 2009), and shared the same investigation area with this study. Zhang et al (2015; 2016) 263 studied the ichthyoplankton assemblages in spring (1999-2007) and autumn (1998-2009). In 264 spring, forty-two ichthyoplankton belonging to 23 families were collected. Engraulidae was the 265 most abundant family, including six species and comprising $67.91 \%$ of the total catch (Zhang et 266 al, 2015), while in autumn a total of 969 ichthyoplankton, constituting 33 species from 19 267 families and 10 orders, were collected during the seven sampling autumns in the Yangtze 268 Estuary. This sample included 226 fish eggs and 743 larvae and juveniles (Zhang et al, 2016). 269 Species composition of ichthyoplankton assemblages in spring showed a descending trend with 27020 species in 1999 (Zhu et al, 2002), 31 in 2001(Zhang et al, 2015), 12 in 2004 (Zhang et al, 271 2015), 17 in 2007 (Zhang et al, 2015) and only 10 in 2012 (the present study). The comparison 272 of these studies reveals that species composition of ichthyoplankton assemblages have been 273 suffering a decline in numbers (Fig 5). Composition and numbers of fresh waters species in this 274 study were less than the investigation results of 2007 (Liu and Xian, 2009; Zhang et al, 2015); only $P$. engrauli was collected. This phenomenon indicated that the composition and numbers of fresh water species have been experiencing a significant decline due to the impact of anthropogenic activity and a change in the natural environment. Zhong et al (2007) has presented that salinity in the Yangtze Estuary and its adjacent waters was significantly influenced by surface runoff, which may result in the decline of fresh water species.

The abundance of ichthyoplankton assemblage in this study was highly concentrated on the dominant species, E. japonicus, which was the commonly identified member of the ichthyoplankton assemblages (Harrison and Whitfield, 1990; Whitfield, 1999). E. japonicus resources have declined dramatically based on the comparison in May of 1999, 2001, 2004, and 2007 (Zhang et al, 2015), and May and June of 2008 (Shan and Jin, 2011). Nevertheless, this study showed that the quantity of E. japonicus resources in every season of 2012 was increasing, 
287

288

289

290

291

292

293

294

295

296

297

298

299

300

301

302

303

304

305

306

307

308

309

310

311

312

313

resources had relatively steady fluctuations in quantity as a result of climate and environment changes, which were mainly caused by water circulation and fluctuations in temperature. Although Watanabe did not point out the duration of the fluctuation, this conclusion was also supported by the investigation results in this study.

Based on the results of this study and the comparison with the results of other scholars, the community structure of ichthyoplankton assemblages in the Yangtze Estuary have fluctuated greatly over a short period of time .This phenomenon is related to the use of coastal water in different months by dominant species for breeding and feeding (Shan and Jin, 2011).However, the sensitivity of the different species to different disruptive factors such as fishing and environmental changes, was also species-dependent and related to ecological niche and habits variations among species.

\section{Biodiversity and its spatial-temporal variation}

In this study, the biodiversity indexes in each season showed significant difference, but all the indexes were relatively low (Table 3). The investigation in 2007 (Zhang et al, 2015, 2016) collected 52 fish eggs and 638 larvae in the spring, 3973 fish eggs and 1342 larvae in the summer, and 6 fish eggs and 450 larvae in the autumn, which were significantly greater than the results in this study in terms of quantity and species composition. Significant differences existed in the spatial and temporal variation of ichthyoplankton assemblages and biodiversity in the Yangtze Estuary from 2007 to 2012. Furthermore, the composition of dominant species in different seasons presented clear variation between 2007 and 2012. In 2007, A. bleekeri, C. mystus, and E. japonicus were the dominant species in the spring, E. japonicus, C. mystus, and $S$. elongata were the dominant species in the summer, and $H$. prognathous, $E$.japonicus and $C$. stigmatias were the dominant species in the autumn. As for 2012: E. japonicus was the dominant species in the spring, E. japonicus and C. nasus were the dominant species in the summer, and $A$. bleekeri was the dominant species in the autumn.

Most of the marine fish's spawning season occurred in the spring and summer, which brings 
314 the abundance of ichthyoplankton assemblages to their maximum point in this period (Young 315 and Potter, 2003; Sabatés et al, 2007). In this study, the abundance and the number of species 316 were highest in the spring, which was consistent with the above conclusion. However, due to the 317 high concentration of E. japonicus in the spring, accounting for $93.80 \%$ of the total abundance, 318 the diversity indexes in the spring was less than summer and autumn.

319 The seasonal variation of biodiversity in the estuary is mainly dependent upon the selection of 320 reproductive areas by grown fish (Hernández et al, 2003) as well as the influence of seasonal

321

322 variation on the water environment in the spawning area on spawning behavior (Lam, 1983). With the increasing intensity of fishing, a variety of fish reached sexual maturity earlier, which led to the spawning period occurring earlier than before. This effect caused the peak abundance value of ichthyoplankton to occur earlier than before, which may be one of the reasons for seasonal variation in ichthyoplankton abundance in the Yangtze Estuary. The environment in the Yangtze Estuary is complicated and changeable with rapid, drastic fluctuations (Luo and Shen, 1994), which prevents the fish from adapting to environmental changes in time, hence the assemblage biodiversity of ichthyoplankton was relatively low.

\section{Relationship between the distribution of ichthyoplankton assemblages and environmental}

\section{factors}

Distribution pattern of ichthyoplankton assemblages in the estuary were affected by both abiotic factors and environmental factors (Zhu et al, 2002). In general, salinity was the major factor which determined the structural changes of plankton communities in the estuaries (Wooldridge, 1999). Due to the specific geographical conditions and the inflow of fresh water into the estuary, salinity showed a clear gradient corresponding to the direction of the runoff. Ichthyoplankton assemblages altered according to the variation of salinity content. CCA ordination results indicated that the key factor affecting the assemblage structure of ichthyoplankton was not salinity but Chla, results that conflicted with studies from Kushlan (1976), Thiel et al (1995), and Fraser (1997). The salinity condition in the Yangtze Estuary was significantly influenced by the surface runoff which could result in the decline of fresh water 
341 species (Zhong et al, 2007). In the present work, only one fresh water species was collected and 342 other species are not sensitive to the variation of salinity. This may be the reason that salinity is 343 not the key factor. Due to the fluctuation of the water environment and species composition in 344 different season, the influence of environmental factors was not consistent among different 345 seasons and years. Harris et al (1999) presented that DO was the leading indicator accounting for 346 the variation of the community structure and abundance of ichthyoplankton assemblages, which 347 was also correspond with conclusions made by other scholars (Castillo-Rivera et al, 2002). In 348 this study, DO was also confirmed as the dominant factor affecting the assemblage structure in 349 the Yangtze Estuary. Temperature, nutrient content, COD, $\mathrm{pH}$ also made significant 350 contributions to the assemblage structures. The CCA ordination only explained $14.4 \%$ and $65.6 \%$ 351 of the variation in species and environment, respectively, thus, more biotic factors and 352 environmental factors need to be collected in later investigations to understand the environmental-biological relationships.

\section{Conclusion}

Across the four surveys conducted in 2012, 3688 individuals of 15 species were collected. We found that significant seasonal differences occurred in the species number and abundance of ichthyoplankton assemblages in the Yangtze Estuary with low biodiversity. Chla was the key environmental factor affecting the assemblage structure of ichthyoplankton in 2012, which was different than the results of previous research.

With the rapid development of industrialization, urbanization, and marine fishery, ichthyoplankton resources are declining significantly, which may strengthen the trend toward the simplification of fishery resources in the Yangtze Estuary. Protection of fishery resources and continuous tracking and monitoring are imperative in the Yangtze Estuary.

\section{Acknowledgement}

We thank all the editors and reviewers for their constructive comments on the present work. 


\section{References}

Azeiteiro UM, Bacelar-Nicolau L, Resende P, Goncalves F, Pereira MJ.2006. Larval fish distribution in shallow coastal waters off North Western Iberia (NE Atlantic). Estuarine, Coastal and Shelf Science 69: 554-566.DOI: 10.1016/j.ecss.2006.05.023

Blaxter JHS.1992. The effect of temperature on larval fishes. Netherlands Journal of Zoology 42: 336-357. DOI: $10.1163 / 156854291 X 00379$.

Castillo-Rivera Manuel, Zavala-Hurtado José Alejandro, Zárate Rocío. Exploration of spatial and temporal patterns of fish diversity and composition in a tropical estuarine system of Mexico [J]. Reviews in Fish Biology and Fisheries, 2002, 12 (2): 167-77.

Chai Chao, Yu Zhiming, Shen Zhiliang, Song Xiuxian, Cao Xihua, Yao Yun. Nutrient characteristics in the Yangtze estuary and the adjacent East China Sea before and after impoundment of the Three Gorges Dam [J]. Science of the Total Environment, 2009, 407 (16): 4687-95.

Cheng Qingtai, Zheng Baoshan. Systematic synopsis of Chinese fishes [M]. Science press, 1987.

Donglai Yang, Guangzong Wu, Jiren Sun. The inveatigation of pelagic eggs, larvae and juveniles of fishes at the mouth of the CHANGJIANG RIVER and adjacent areas [J]. OCEANOLOGIA ET LIMNOLOGIA SINICA, 1990, (04): 346-55.

Faria A, Morais P, Chı'charo MA. 2006. Ichthyoplankton dynamics in the Guadiana estuary, South-East Portugal. Estuarine, Coastal and Shelf Science 70: 85-97.DOI: 10.1016/j.ecss.2006.05.032.

Fraser Thomas H. Abundance, seasonality, community indices, trends and relationships with physicochemical factors of trawled fish in upper Charlotte Harbor, Florida [J]. Bulletin of Marine Science, 1997, 60 (3): 739-63.

Gray CA. 1993. Horizontal and vertical trends in the distributions of larval fishes in coastal waters off central New South Wales, Australia. Marine Biology 116: 649-666. DOI: 10.1007/BF00355483.

Harris SA, Cyrus DP, Beckley LE. The larval fish assemblage in nearshore coastal waters off the St Lucia Estuary, South Africa [J]. Estuarine, Coastal and Shelf Science, 1999, 49 (6): 789-811.

Harrison TD, Whitfield AK. Composition, distribution and abundance of ichthyoplankton in the Sundays River estuary [J]. African Zoology, 1990, 25 (3): 161-8. 
395

396

397

398

399

400

401

402

403

404

405

406

407

408

409

410

411

412

413

414

415

416

417

418

419

420

421

Hernández Miranda E, Palma AT, Ojeda FP. Larval fish assemblages in nearshore coastal waters off central Chile: temporal and spatial patterns [J]. Estuarine, Coastal and Shelf Science, 2003, 56 (5): 1075-92.

Islam MS, Hibino M, Tanaka M. 2006. Distribution and diets of larval and juvenile fishes: Influence of salinity gradient and turbidity maximum in a temperate estuary in upper Ariake Bay, Japan. Estuarine, Coastal and Shelf Science 68: 62-74.DOI: 10.1016/j.ecss.2006.01.010.

Kushlan James A. Environmental stability and fish community diversity [J]. Ecology, 1976, 57 (4): 821-5.

Lam TJ. Environmental Influences on Gonadal Activity in Fish [J]. Fish physiology, 1983, 9 65-116.

Leis JM. 1991. The pelagic stage of reef fishes: the larval biology of coral reef fishes. In: Sale, P. E (ed.) The ecology of fishes on coral reefs. Academic Press, New York, pp183-230

Liu SD, Xian WW, Liu Dong. Characteristics of ichthyoplankton assemblages in Yangtze estuary and adjacent waters in spring [J]. The journal of applied ecology, 2008, 19 (10): 2284-92.

Liu Shude, Xian Weiwei. Temporal and spatial patterns of the ichthyoplankton community in the Yangtze Estuary and its adjacent waters [J]. Biodiversity Science, 2009, (02): 151-9.

Ludwig John A, Reynolds James F. Statistical ecology: a primer in methods and computing [M]. John Wiley \& Sons, 1988.

Luo Bingcheng, Shen Huanting. Impacts of the Three Gorges Project on Estuarine Ecology and Environment [M]. Beijing.(in Chinese): Science Press, 1994.

Qian Yingning, Ma Keping. The measurement of community diversity.In: Principles and Methodologies of Biodiversity Studies [M]. Beijing. (in Chinese); Chinese Science and Technology Press. 1994.

Rakocinski CF, LyczkowskiShultz J, Richardson SL. 1996. Ichthyoplankton assemblage structure in Mississippi sound as revealed by canonical correspondence analysis. Estuarine, Coastal and Shelf Science 43:237-257. DOI: 10.1006/ecss.1996.0067.

Sabatés Aea, Olivar MP, Salat J, Palomera I, Alemany F. Physical and biological processes controlling the distribution of fish larvae in the NW Mediterranean [J]. Progress in Oceanography, 2007, 74 (2): 355-76.

Shan XiuJuan, Jin XianShi. DIVERSITY OF FISH COMMUNITY STRUCTURE IN THE SPRING-TIME OFFSHORE WATERS AT THE YANGTZE ESTUARY [J]. OCEANOLOGIA ET LIMNOLOGIA SINICA, 2011, (01): 32-40. 
422 Thiel R, Sepulveda A, Kafemann R, Nellen W. Environmental factors as forces structuring the fish community 423 of the Elbe Estuary [J]. Journal of Fish Biology, 1995, 46 (1): 47-69.

424 Wantiez L, Hamerlin-Vivien M, Kulbicki M. 1996. Spatialand temporal variation in a soft-bottom fish assemblages in St.Vincent Bay, New Caledonia. Marine Biology 125:801-812. DOI: 
449 Shanghai. (in Chinese): Shanghai Science and Technology Press 1985.

450 Zhong Junsheng, Wu Meiqin, Lian Qingping. Composition of fish larvae and juveniles in spring and summer 451 in surf zone of Yangtze estuary [J]. Journal of Fishery Sciences of China, 2007, (03): 436-43.

452 Zhu Xinhua, Liu Dong, Sha Xueshen. Relationshio between community structure of ichthyoplankton and 453 environmental factors in the estuary of Changiiang River in spring [J]. STUDIA MARINA SINICA, 2002, $454 \quad$ (00): 169-79. 


\section{Table 1 (on next page)}

Presence $(+)$ of species in ichthyoplankton samples in the present study 


\begin{tabular}{|c|c|c|c|c|c|c|}
\hline \multirow{2}{*}{ Species } & \multirow{2}{*}{ Code } & \multirow{2}{*}{ Ecotype } & \multicolumn{4}{|c|}{ Month } \\
\hline & & & Feb & May. & Aug. & Nov. \\
\hline \multicolumn{7}{|l|}{ Engraulidae } \\
\hline Engraulis japonicus & Enja & marine & & $t$ & $t$ & $t$ \\
\hline Anchoviella commersoni & Anco & coastal & & $t$ & $t$ & $t$ \\
\hline Coilia nasus & Cona & brackish water & & & $t$ & $t$ \\
\hline Coilia mystus & Comy & brackish water & & $t$ & $t$ & $t$ \\
\hline \multicolumn{7}{|l|}{ Cyprinidae } \\
\hline Pseudolaubuca engraulis & Psen & fresh water & & & $t$ & \\
\hline \multicolumn{7}{|l|}{ Sciaenidae } \\
\hline Larimichthys polyactis & Lapo & coastal & & $t$ & & \\
\hline \multicolumn{7}{|l|}{ Scombridae } \\
\hline Scomber japonicus & Scja & marine & & $t$ & & \\
\hline \multicolumn{7}{|l|}{ Trichiuridae } \\
\hline Trichiurus japonicus & Trja & marine & & & & $t$ \\
\hline \multicolumn{7}{|l|}{ Atherinidae } \\
\hline Allanetta bleekeri & $A l b l$ & coastal & & $t$ & $t$ & $t$ \\
\hline \multicolumn{7}{|l|}{ Scorpaenidae } \\
\hline Minous monodactylus & Mimo & coastal & & $t$ & $t$ & \\
\hline \multicolumn{7}{|l|}{ Triglidae } \\
\hline Chelidonichthys spinosus & Trfa & brackish water & & + & $t$ & $t$ \\
\hline \multicolumn{7}{|l|}{ Hemiramphidae } \\
\hline Hemiramphus sajori & Hesa & brackish water & & & & + \\
\hline \multicolumn{7}{|l|}{ Syngnathidae } \\
\hline Syngnathus acua & Syac & marine & & & & $t$ \\
\hline \multicolumn{7}{|l|}{ Lophiidae } \\
\hline Lophius litulon & Loli & marine & & + & & \\
\hline \multicolumn{7}{|l|}{ Tetraodontidae } \\
\hline Takifugu sp. & Tasp & brackish water & & $t$ & & \\
\hline
\end{tabular}


Table 2 (on next page)

Composition of dominant ichthyoplankton species in different seasons 
Table 2 Composition of dominant ichthyoplankton species in different seasons

\begin{tabular}{|c|c|c|c|c|c|c|}
\hline \multirow[b]{2}{*}{ Dominant species } & \multicolumn{2}{|c|}{ Spring } & \multicolumn{2}{|c|}{ Summer } & \multicolumn{2}{|r|}{ Autumn } \\
\hline & IRI & $\begin{array}{l}\text { Percentage of } \\
\text { quantity (\%) }\end{array}$ & IRI & $\begin{array}{l}\text { Percentage of } \\
\text { quantity (\%) }\end{array}$ & IRI & $\begin{array}{c}\text { Percentage of quantity } \\
(\%)\end{array}$ \\
\hline Engraulis japonicus & 5120.99 & 90.2 & 1532.11 & 74.61 & 19.74 & 3.95 \\
\hline Coilia mystus & 158.99 & 3.6 & 40.37 & 10.01 & 3.29 & 1.32 \\
\hline Allanetta bleekeri & 11.27 & 1.13 & 1.15 & 0.46 & 52.63 & 5.26 \\
\hline Chelidonichthys spinosus & 4.22 & 0.85 & 1.15 & 0.46 & 3.29 & 1.32 \\
\hline Anchoviella commersoni & 2.11 & 0.42 & 1.15 & 0.46 & 26.32 & 5.26 \\
\hline Larimichthys polyactis & 1.52 & 0.61 & & & & \\
\hline Scomber japonicus & 0.12 & 0.025 & & & & \\
\hline Minous monodactylus & 0.12 & 0.025 & & & & \\
\hline Lophius litulon & 0.12 & 0.025 & & & & \\
\hline Takifugu sp. & 0.12 & 0.025 & & & & \\
\hline Coilia nasus & & & 2.30 & 2.02 & 19.74 & 3.95 \\
\hline Pseudolaubuca engraulis & & & 300.25 & 12.00 & & \\
\hline Hemirhamphus sajori & & & & & 39.47 & 5.26 \\
\hline Syngnathus acua & & & & & 13.16 & 2.63 \\
\hline Trichiurus japonicus & & & & & 3.29 & 1.32 \\
\hline
\end{tabular}




\section{Table 3(on next page)}

Diversity index of ichthyoplankton in different seasons

$P<0.01$, Numbers with different superscript are significantly different with each other. 
1 Table 3 Diversity index of ichthyoplankton in different seasons

\begin{tabular}{ccccc}
\hline & Spring & Summer & Autumn & Winter \\
\hline Species richness $(D)$ & $0.79 \pm 0.05^{\mathrm{A}}$ & $0.74 \pm 0.08^{\mathrm{A}}$ & $1.62 \pm 0.11^{\mathrm{B}}$ & $0.00 \pm 0.00^{\mathrm{C}}$ \\
Pielou evenness index $\left(J^{\prime}\right)$ & $0.10 \pm 0.06^{\mathrm{A}}$ & $0.38 \pm 0.08^{\mathrm{B}}$ & $0.49 \pm 0.05^{\mathrm{B}}$ & $0.00 \pm 0.00^{\mathrm{C}}$ \\
Shannon-Wiener index $\left(H^{\prime}\right)$ & $0.19 \pm 0.05^{\mathrm{A}}$ & $0.61 \pm 0.09^{\mathrm{B}}$ & $1.04 \pm 0.10^{\mathrm{C}}$ & $0.00 \pm 0.00^{\mathrm{D}}$ \\
\hline
\end{tabular}

2 Note: $\mathrm{P}<0.01$, Numbers with different superscript are significantly different with each other. 


\section{Table 4(on next page)}

Conditional effects and correlations of environmental variables with the CCA 
Table 4 Conditional effects and correlations of environmental variables with the CCA axes

\begin{tabular}{|c|c|c|c|c|}
\hline Environmental factors & Lambda A & $\mathrm{P}$ & Axis 1 & Axis 2 \\
\hline Chla & 0.23 & 0.046 & 0.7541 & 0.1330 \\
\hline $\mathrm{pH}$ & 0.16 & 0.148 & -0.0108 & 0.0124 \\
\hline DO & 0.13 & 0.334 & -0.0649 & -0.0482 \\
\hline $\mathrm{D}$ & 0.1 & 0.414 & 0.0208 & 0.1146 \\
\hline $\mathrm{TP}$ & 0.11 & 0.396 & 0.4464 & 0.2961 \\
\hline COD & 0.09 & 0.610 & 0.1636 & -0.0699 \\
\hline SPM & 0.08 & 0.514 & 0.6435 & 0.1287 \\
\hline $\mathrm{TN}$ & 0.14 & 0.298 & 0.0251 & -0.1837 \\
\hline $\mathrm{T}$ & 0.08 & 0.64 & 0.1195 & 0.0236 \\
\hline S & 0.08 & 0.682 & -0.0912 & 0.1521 \\
\hline
\end{tabular}

2 
Figure 1

Location of survey stations of ichthyoplankton in Yangtze estuary

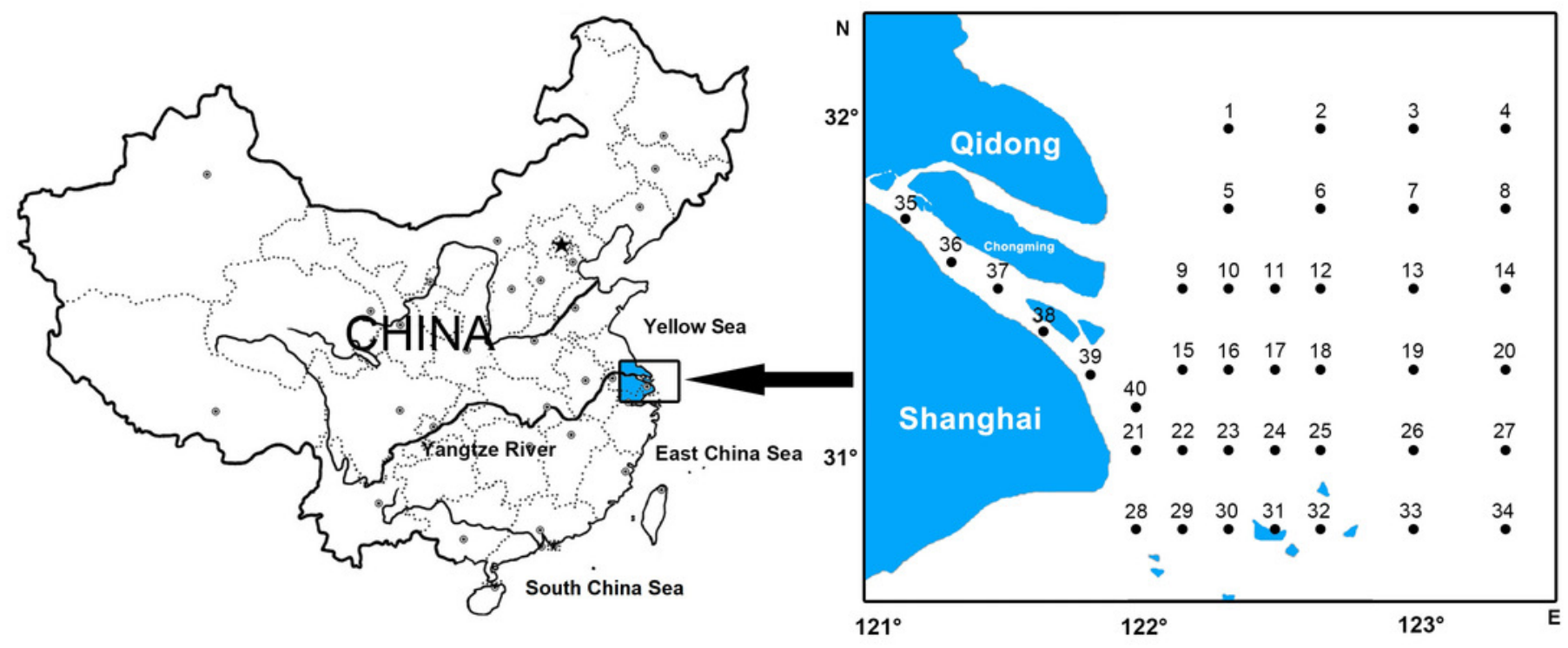


Figure 2

Distribution of ichthyoplankton abundance in the present study

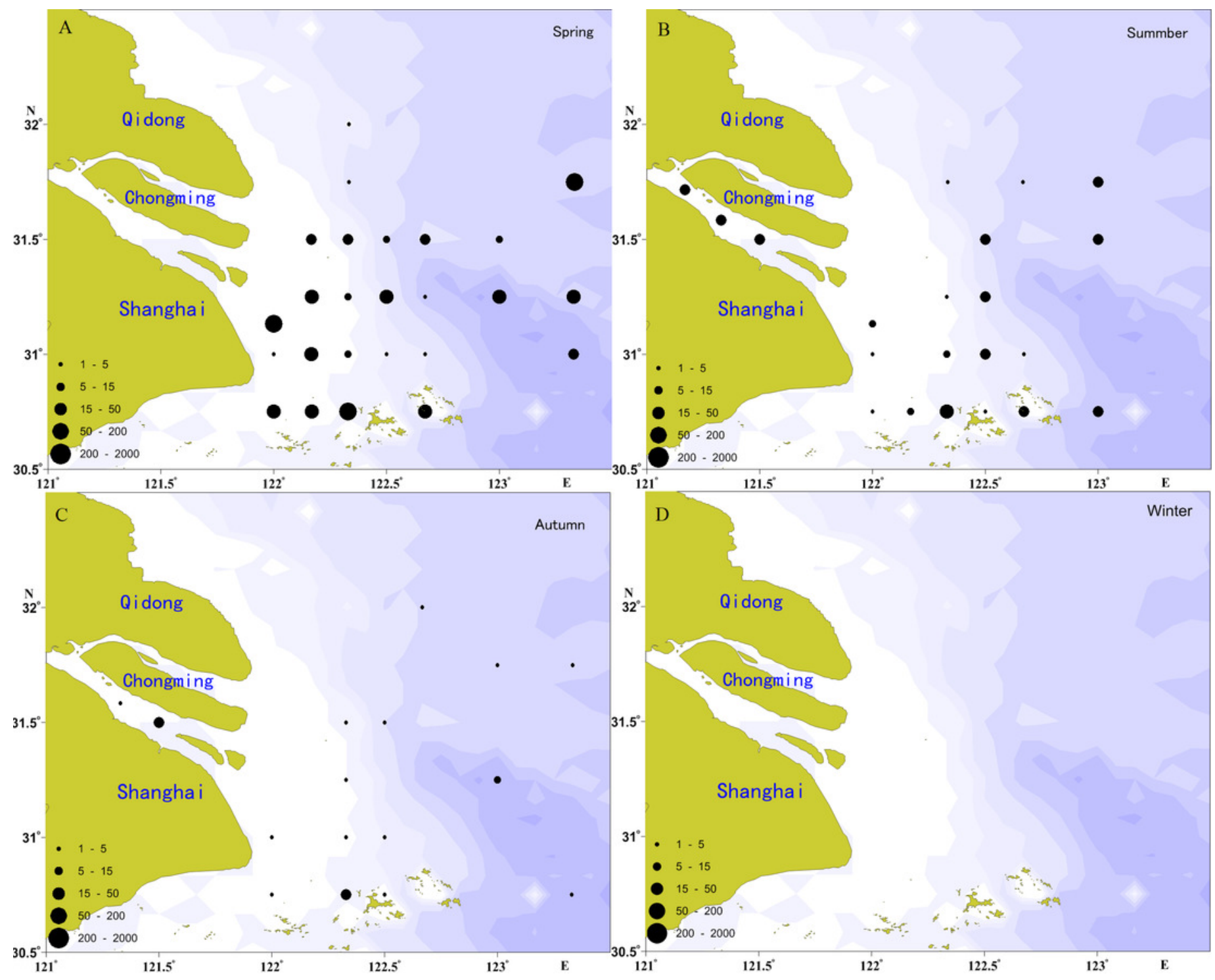


Figure 3

CCA biplot of sampling stations

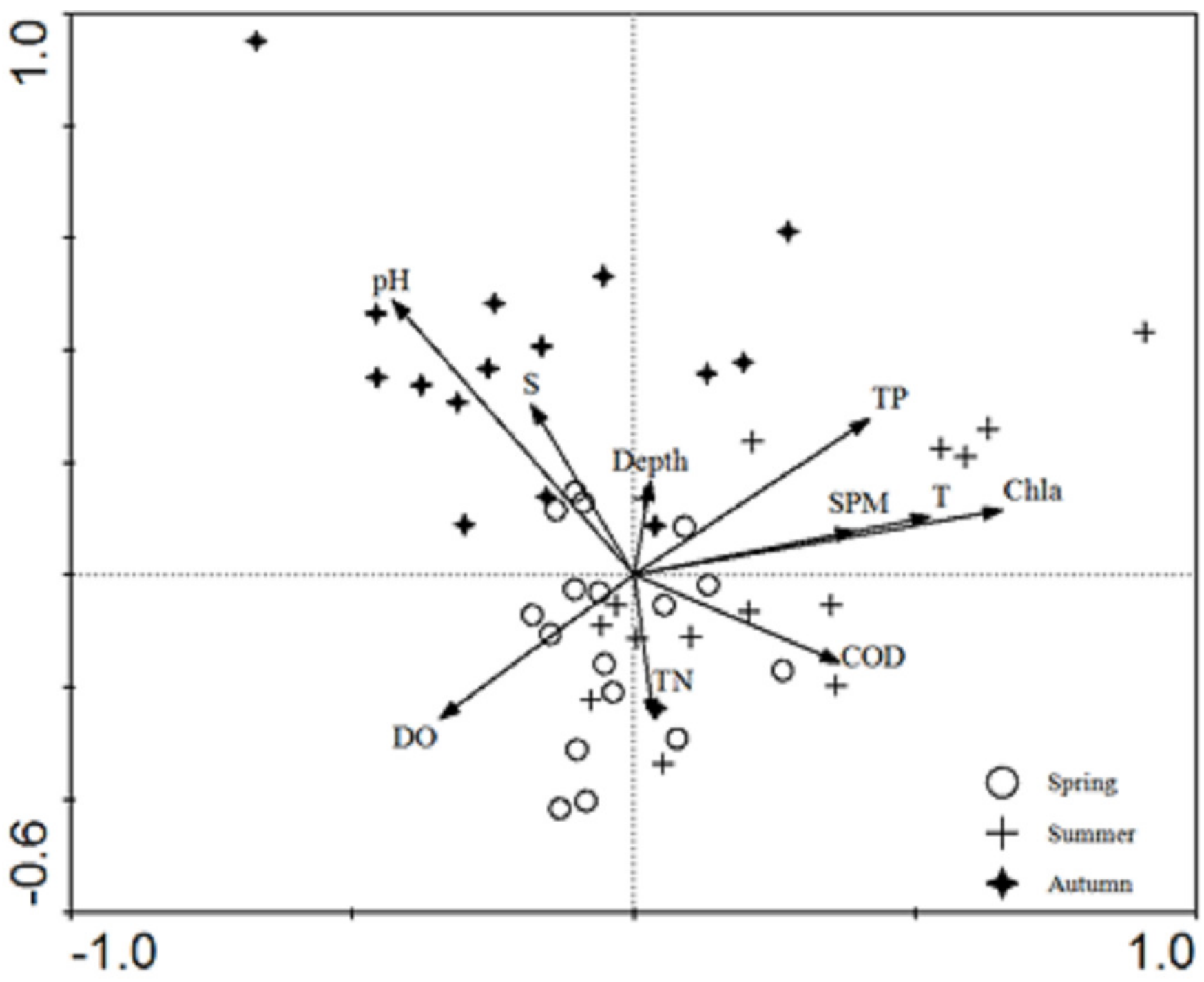


Figure 4

CCA biplot of ichthyoplankton species

The italic characters indicate the abbreviate name of the species as shown in Table 1

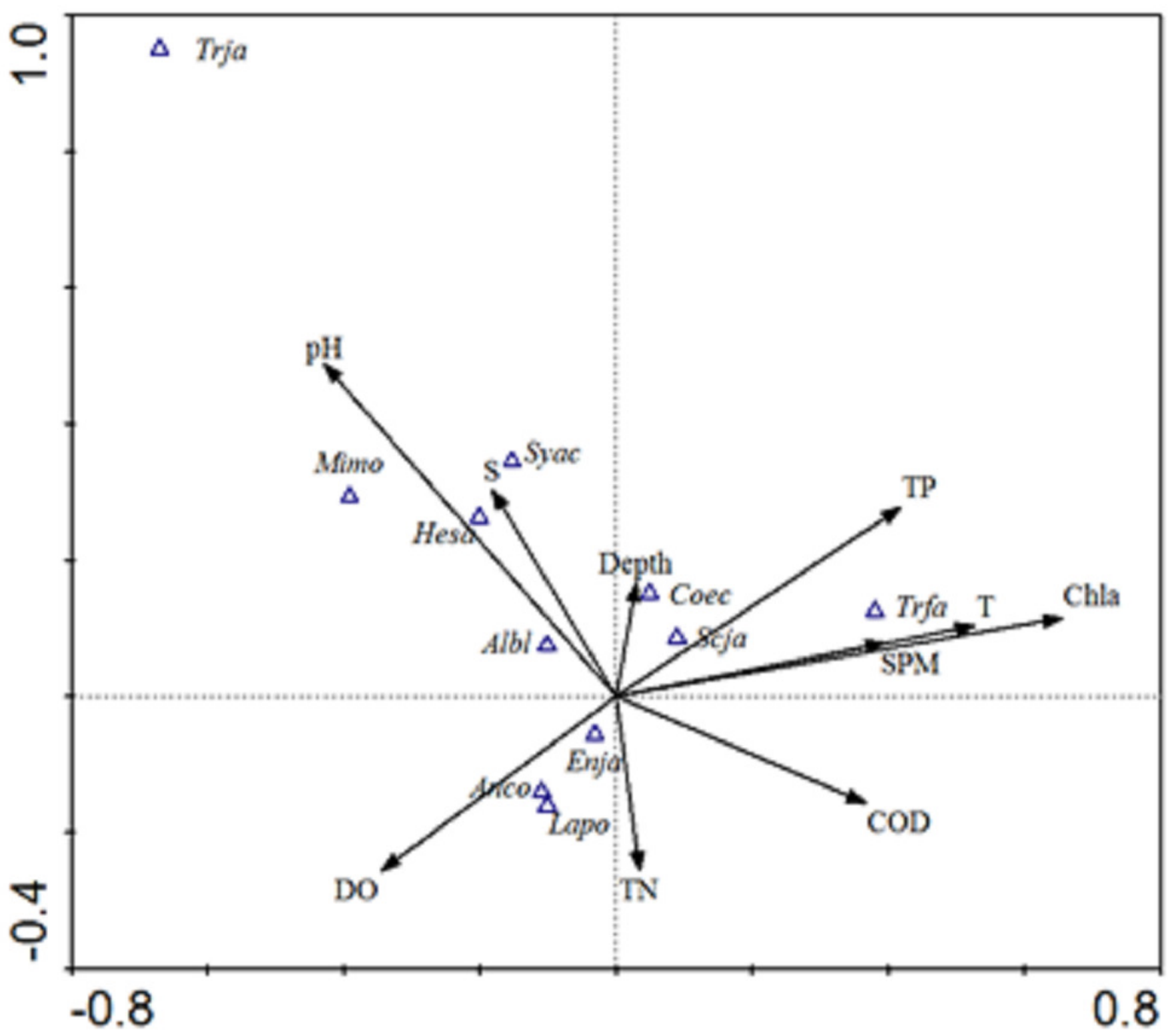




\section{Figure 5}

Spring long-term variation of the ichthyoplanton in Yangtze Estuary

The data for 1999-2011 was referenced from Zhang et al 2015 and 2016.

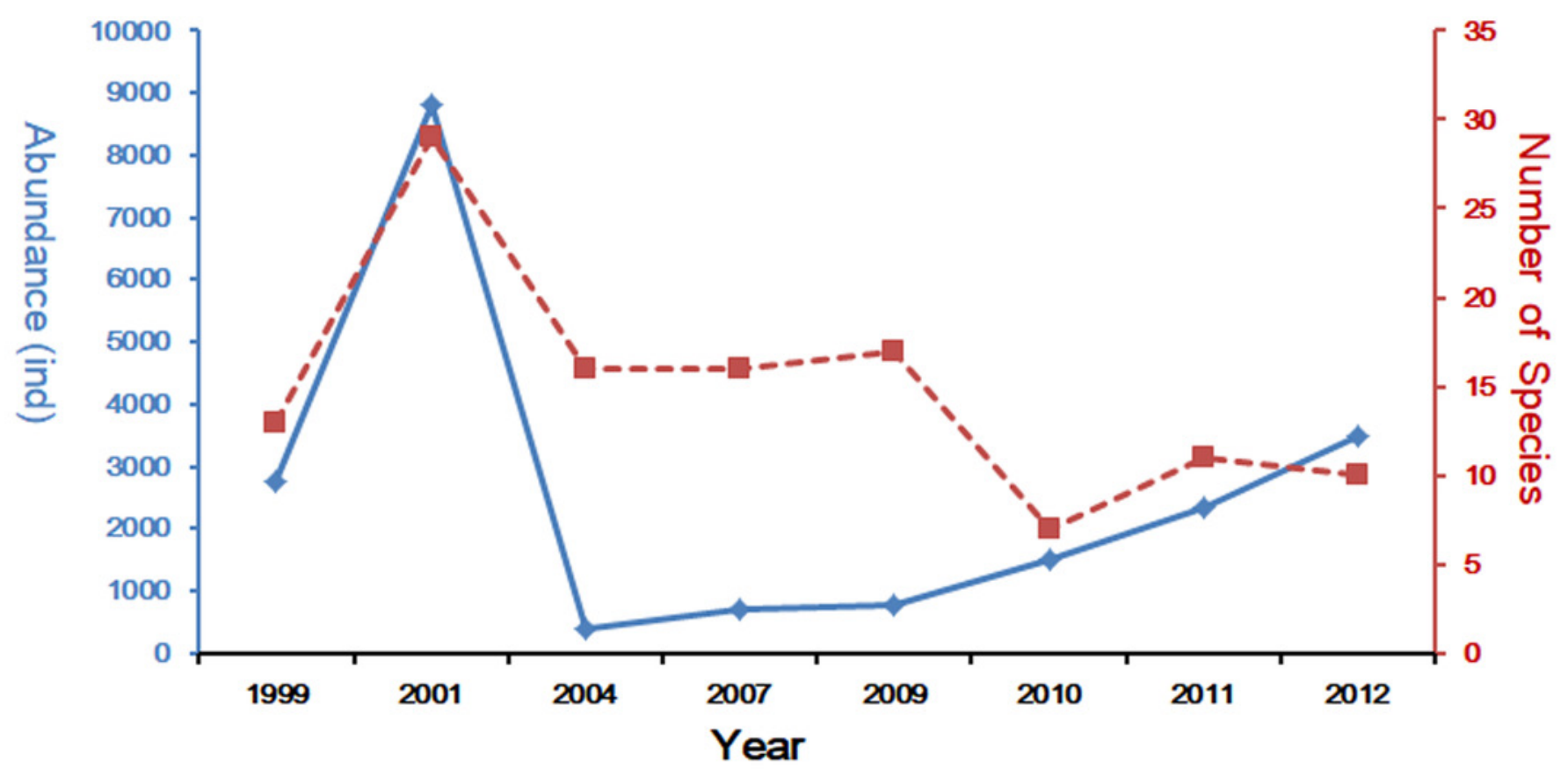

